\title{
Caracterização da participação das famílias no apoio pelas equipas locais de intervenção
}

\section{Families participation in the support provided by the local early intervention}

\author{
teams \\ Marta Joana de Sousa Pinto*, Ana Maria Serrano** \\ * Politécnico do Porto, Escola Superior de Saúde; Sistema Nacional de Intervenção Precoce na Infância, Equipa Local de Intervenção \\ Precoce Gaia Sul, ** Universidade do Minho, Instituto de Educação
}

\begin{abstract}
Resumo
Estudos nacionais e internacionais respeitantes à participação das famílias nos serviços de intervenção precoce conduziram a um projeto de investigação em que se pretende compreender a participação das famílias nos apoios prestados pelas Equipas Locais de Intervenção. Desta forma, dezoito familiares de crianças, entre os 0 e os 6 anos de idade, preencheram a Escala de Práticas de Capacitação. Os dados foram recolhidos entre março e dezembro de 2016. Neste artigo, pretendemos apresentar os resultados obtidos com a EPS pelos membros da familia, caracterizando a perceção da participação das famílias.
\end{abstract}

Palavras chave: intervenção precoce, família, participação ativa, apoio, enabling practices scale.

\begin{abstract}
National and international studies about the participation of families in early intervention services have led to a research that intends to understand the participation of families in the support provided by the Local Intervention Teams. In this way, eighteen family members of children between the ages of 0 and 6 were contacted and completed the Enabling Practices Scale. Data collection took place between March and December 2016. In this article, we intend to present the results obtained with the completion of the EPS by the family members, characterizing the perception of the participation of the families.

Keywords: early intervention, family, involvement, support, enabling practices scale.
\end{abstract}

As Práticas Centradas na Família (PCF) são definidas como um conjunto de práticas que reconhecem a centralidade da família e promovem as suas forças e capacidades (Trivette \& Dunst, 2005). Dunst (2000) e seus colaboradores têm desempenhado um papel fundamental na operacionalização das PCF pelos profissionais de Intervenção Precoce (IP) junto de crianças e famílias. De acordo com este modelo identificam-se como alvos prioritários da IP a promoção de oportunidades de aprendizagem das crianças, o apoio aos pais e a mobilização de recursos familiares e da comunidade. As famílias são apoiadas, partindo dos seus pontos fortes, únicos e diferenciados enquanto indivíduos e famílias. O papel da família é respeitado, sendo ela a principal unidade da intervenção e o elemento-chave no processo de tomada de decisão e na prestação de cuidados à criança.

De acordo com as recomendações da Division for Early Childhood (2014), por Dunst, Boyd, Trivette e Hamby (2002), e Carvalho et al. (2016) entendemos a participação das famílias nos apoios prestados pelas equipas de IP como a participação ativa das famílias em todos os momentos do apoio prestado pelo profissional. A família deve ter o conhecimento informado e a oportunidade de tomar decisões aquando todos os momentos do apoio. O profissional de IP deve atuar como um facilitador, partilhando todas as informações com os pais, criando oportunidades para que todos os membros da família possam demonstrar e adquirir competências e incentivá-los a tomar decisões acerca dos recursos e apoios desejados.

Dunst e Trivette identificaram três componentes profissionais que caracterizam as práticas de ajuda eficaz nos programas centrados na família, ou seja a prestação de ajuda que por um lado potencia competências e, por outro, tem repercussões no empowerment; nomeadamente a qualidade técnica, as práticas relacionais e as práticas participativas. A qualidade técnica inclui os conhecimentos teóricos e práticos do profissional acerca da área em que trabalha. É o resultado da sua formação e da sua experiência profissional (Carvalho et al., 2016).

As práticas relacionais dizem respeito às características e representações interpessoais do profissional que influenciam os aspetos relacionais do apoio, nomeadamente as convicções e crenças positivas sobre as competências e capacidades da família (Carvalho, 2004). Carvalho et al. (2016) referem que são a base para o profissional reconhecer e validar os pontos fortes existentes e assim poder usar as capacidades da família para melhorar o seu funcionamento.

As práticas participativas surgiram posteriormente, contribuindo para fortalecer as competências da família e promover novas capacidades e influenciar de forma positiva o controlo que a família experiencia no seu 
funcionamento familiar (Carvalho et al., 2016). As práticas participativas referem-se aos comportamentos do profissional que visam a participação da família no processo de tomada de decisão e de escolha informada e no recurso às forças existentes e às competências em desenvolvimento para alcançar os recursos, apoios e serviços desejados pela família. Estas práticas promovem a participação da família na relação com os profissionais e têm sido descritas como as práticas que têm mais hipóteses de resultar em avaliações positivas da família acerca das suas capacidades (Dunst \& Espe-Sherwindt, 2016; Carvalho et al., 2016).

Verificamos a importância de compreender as interações entre os profissionais, as famílias e as crianças durante a intervenção para verificar a participação da família nos programas de IP (Dunst, Bruder \& EspeSherwindt, 2014; Peterson, Luze, Eshbaugh, Jeon \& Kantz, 2007). Conhecer melhor como ocorre a participação das famílias no apoio prestado pelos programas de IP em Portugal, de acordo com o que são as PCF e identificar os fatores que contribuem para a participação das mesmas famílias, pode guiar os profissionais a identificar as técnicas e estratégias de intervenção que mantêm os pais participantes ativos nos serviços que suportam a aprendizagem e o desenvolvimento do seu filho.

\section{Métodos}

Neste artigo pretendemos apresentar os resultados obtidos com o preenchimento da Escala de Práticas de Capacitação - "Enabling Practices Scale" (EPS) ${ }^{1}$ (Dempsey, 1995; Dunst, Trivette \& Hamby, 2006). pelos familiares apoiados pelas Equipas Locais de Intervenção (ELI), do Serviço Nacional de Intervenção Precoce na Infância (SNIPI), das cinco regiões de Portugal Continental.

Os dados foram recolhidos entre março e dezembro de 2016 e fazem parte de um conjunto de dados recolhidos no âmbito de um estudo de caso qualitativo que serve a investigação de doutoramento.

Fizeram parte da amostra dezoito familiares, que tinham em média 36 anos de idade (d.p. 6,48). A maioria dos familiares $(\mathrm{N}=9)$ eram casados ou viviam em união de facto. No que respeita ao nível de escolaridade, verificamos que sete familiares terminaram o secundário e outros sete um curso universitário ou superior. Os restantes tinham um nível de escolaridade inferior ao terceiro ciclo. Apenas três familiares, dos dezoito contactados referiram estar desempregados.

As crianças apoiadas eram na sua maioria rapazes e tinham em média 44 meses de idade (d.p. 18,46). Dez das crianças da amostra frequentavam o pré-escolar, duas frequentavam a creche e as restantes ficavam em casa aos cuidados de pelo menos um familiar. A maioria das visitas, pelo mediador de caso, aconteciam em contexto de pré-escolar, sendo que apenas em quatro famílias verificamos que as visitas eram em domicílio. De uma forma geral o apoio acontecia semanalmente. Apenas uma família referiu que o apoio era agendado de acordo com as suas necesidades.

As referenciações à IP foram feitas na sua maioria pelo hospital ou centro de saúde $(\mathrm{N}=10)$. Verificamos que quatro familiares, não estando a obter respostas face às suas preocupações procuraram ativamente as equipas.

Utilizamos a EPS para ser preenchida pelas famílias de crianças apoiadas pelas ELI. A EPS foi desenvolvida por Dempsey (1995), tendo por base pressupostos teóricos de práticas de capacitação e corresponsabilização, com o objetivo de ser um instrumento que pretende medir práticas que capacitem a família, utilizadas pelos profissionais de serviços de intervenção com famílias e indivíduos com necessidades especiais (Dempsey, 1995; Dunst, Trivette \& Hamby, 2006). Este questionário tem sido utilizado na investigação, em diferentes países, para estudar práticas de capacitação e corresponsabilização, com o objetivo de avaliar e monitorizar o nível de participação dos pais nos programas de IP (Dunst, Trivette \& Hamby, 2006), que consideramos de acordo com o objetivo da investigação.

A EPS foi preenchida por famílias que estavam a ser apoiadas há pelo menos seis meses e até ao término do apoio, cumprindo os critérios de inclusão. Para isso, as famílias indicaram numa Escala de Likert, selecionando uma de cinco respostas possíveis (1- Não é de todo verdade, 2 - Na maior parte das vezes não é verdade, 3 Um pouco verdade, 4 - Na maior parte das vezes é verdade, e 5 - Totalmente verdade), o valor que corresponde a essa mesma relação (Dunst, Trivette \& Hamby, 2006).

Os resultados obtidos foram submetidos a análise estatística descritiva, com recurso ao IBM SPSS Statistics 24. Assim, foi calculada a frequência absoluta das respostas obtidas em cada um dos items.

\section{Resultados}

Dos resultados obtidos com o preenchimento da EPS, verificamos que a maioria dos familiares respondeu participar ativamente no apoio que lhe é prestado pelos profissionais de IP, selecionando na sua maioria a opção "5 - Totalmente verdade".

Os items que obtiveram maior frequência absoluta ( $>80 \%)$, na opção "5- Totalmente verdade" foram os items 1 - "A equipa e eu concordamos no que é mais importante no Plano Individual de Intervenção Precoce (PIIP)", 5 - "As sugestões da equipa, para trabalhar com o meu filho, fazem-me sentir confortável", 6 - "A equipa aceita as crenças e valores da minha familia", 9 - "É fácil trabalhar em conjunto com a equipa quando planeamos o PIIP”, 12 - "As sugestões que a equipa faz são positivas", 14 - "A equipa preocupa-se com a minha criança e a minha familia", 18 - "Eu sinto-me confortável em dar opiniões à equipa se ela me pedir ajuda" e 22 - "A equipa aceita com agrado as minhas sugestões", tendo o item 14 alcançado um total de $94 \%$ das respostas. Os items que obtiveram maior frequência absoluta para a opção "4- $\mathrm{Na}$ maior parte das vezes é verdade" foram o 10 - "Eu sinto-

\footnotetext{
${ }^{1}$ Copyright $@$ 1995. Ian Dempsey

Traduzido e Adaptado por Marta Joana de Sousa Pinto no âmbito da Tese de Doutoramento - Estudos da Criança/ Educação Especial, do CIEd Universidade do Minho, com pedido de autorização ao autor.
} 
me o maior responsável pelo progresso da minha criança", 16 - "A equipa antecipa as preocupações e necessidades da minha familia" e 17 - "Eu sou o principal responsável pelas importantes mudanças ocorridas na vida da minha criança", tendo o item 16 obtido $50 \%$ das respostas. O item 21 - "Eu decido os objetivos do PIIP" obteve a maior frequência absoluta de respostas para a opção "1 - Não é de todo verdade", com $22 \%$ das respostas, tendo sido o item que obteve a menor frequência absoluta para a opção "5- Totalmente verdade", com $11 \%$ das respostas. Os items 7 - "Eu sou um parceiro igual na relação com os outros membros da equipa", 10 - "Eu sinto-me o maior responsável pelo progresso da minha criança", 13 - "A equipa encorajame a contactar a minha família e os meus amigos quando preciso de conselhos", 15 - "O apoio que a equipa me dá vai de encontro às necessidades da minha familia”, 17 "Eu sou o principal responsável pelas importantes mudanças ocorridas na vida da minha criança", 19 "Seguindo as sugestões da equipa, eu aprendi como lidar com as preocupações da minha familia", 20 - "A equipa oferece ajuda adequada às necessidades da minha familia" e 21, foram os que obtiveram maior variabilidade de respostas no intervalo da escala, tendo sido selecionadas quatro das cinco opções possíveis.

Com os dados obtidos pelo preenchimento da EPS pelos familiares verificamos que as famílias reconhecem que os profissionais as ouvem e se preocupam com elas, respeitando as suas crenças culturais e os seus valores pessoais e reconhecendo e valorizando as forças dos membros da família.

A maioria dos familiares percepciona participar ativamente no apoio prestado, ainda que não se verifique a sua participação em todas as fases do processo de intervenção, mais especificamente na decisão dos objetivos do PIIP e na sua implementação e monitorização no dia-a-dia da familia, Os familiares referem na sua maioria que é fácil trabalhar em conjunto com a equipa quando planeiam o PIIP (83\%), sentem-se confortáveis em dar sugestões à equipa se ela solicitar ajuda $(89 \%)$ e que ambos concordam com o que é mais importante no plano de intervenção (83\%), embora somente $56 \%$ refiram ser parceiros iguais na relação com outros membros da equipa, $67 \%$ refere ter um papel ativo nas decisões mais importantes na elaboração do plano de intervenção e $11 \%$ referem decidir os objetivos do PIIP.

A familia parece reconhecer os resultados positivos do apoio pelos profissionais no desenvolvimento da sua criança, não parecendo no entanto, estar consciente do seu poder na intervenção, de acordo com as respostas obtidas.

\section{Considerações finais}

A relação de colaboração entre os profissionais e as famílias, com base nos principios das PCF, desenvolvese ao longo de todo o processo de apoio, desde o primeiro contacto da familia com a ELI até à altura em que a familia/ criança transita para outro serviço. A familia é um parceiro ativo em todo o apoio prestado e o profissional apoia a familia a assumir o poder que naturalmente possui (Carvalho et al., 2016).
De acordo com os resultados obtidos com a EPS podemos verificar que os profissionais implementam práticas que constroem relações autênticas com as famílias (Práticas Relacionais) e que começam a implementar práticas que promovem as escolhas, o poder de decisão e o envolvimento da familia no apoio prestado (Práticas Participativas).

Temos consciência que estes dados não são representativos do apoio prestado pelos profissionais de IP em Portugal. Eles são parte de um estudo de caso qualitativo no âmbito de uma investigação de doutoramento e pretendem em conjunto, identificar como está a ser prestado o apoio pelos profissionais de IP em Portugal, de acordo com o que são as PCF recomendadas ao nível nacional e internacional.

\section{Referências}

Carvalho, M.L. (2004). Práticas centradas na família na avaliação da criança: Perceções dos profissionais e das famílias do PIP do distrito de Coimbra. Unpublished Mestrado, Instituto de Estudos da Criança da Universidade do Minho, Braga.

Carvalho, L., Almeida, I. C. de, Felgueiras, I., Leitão, S., Boavida, J., Santos, P. C., ... Franco, V. (2016). Práticas recomendadas em intervenção precoce na infância: um guia para profissionais. (1a). Coimbra: Associação Nacional de Intervenção Precoce.

Division for Early Childhood. (2014). DEC recommended practices in early intervention and early childhood special education. Retirado de http://www.dec-sped.org/\%5Cnhttp://www.decsped.org/recommendedpractices

Dempsey, I. (1995). The enabling practices scale: the development of an assessment instrument for disability services. Australia and New Zealand Journal of Developmental Disability, 29, 40-51.

Dunst, C. J. (2000). Corresponsabilização e práticas de ajuda que se revelam eficazes no trabalho com famílias. In A. Serrano \& L. M. Correia (Eds.) Envolvimento parental e intervenção precoce (123141). Porto: Porto Editora.

Dunst, C. J. , Boyd, K., Trivette, C.M., \& Hamby, D. (2002).Family-oriented program models and professional helpgiving practices. Family relations, 51, 221-229.

Dunst, C., Bruder, M., \& Espe-sherwindt, M. (2014). Family capacity-building in early childhood intervention: do context and setting matter? School Community Journal, 24(1), 37-48.

Dunst, C.J., \& Espe-Sherwindt, M. (2016). FamilyCentered Practices in Early Childhood Intervention. In S. L. Odom, B. Reichow, E. Barton, \& B. Boyd (Eds.), Handbook of early childhood special education. New York: Springer.

Dunst, C.J., Trivette, C.M. \& Hamby, D.W. (2006). Technical manual for measuring and evaluating family support program quality and benefits. North Carolina: Winterberry Press.

Peterson, C.A., Luze, G.J., Eshbaugh, E.M., Jeon, H.J. \& Kantz, K.R. (2007). Enhancing parent-child interactions through home visiting: promising practice 
or unfulfilled promise? Journal of Early Intervention, 29 (2), 119-140.

Trivette, C. M. \& Dunst, C. J. (2005). DEC recommended practices: Family-focused practices. In S. Sandall, M. L. Hemmeter, B. J. Smith, \& M. E. McLean (Eds.). DEC recommended practices: a comprehensive guide or pratical application (pp. 107126). Longmont, CO: Sopris West. 